Original Research Paper

\title{
Progressive Damage Modelling of Transverse Impact Behavior of Adhesively Bonded Composite Joints
}

\author{
Dimitrios Athinaios, Konstantinos Tserpes and Giannis Floros \\ Department of Mechanical Engineering and Aeronautics, \\ Laboratory of Technology and Strength of Materials, University of Patras, Greece
}

\begin{abstract}
Article history
Received: 06-01-2020

Revised: $18-02-2020$

Accepted: 02-04-2020

Corresponding Author:

Konstantinos Tserpes

Department of Mechanical

Engineering and Aeronautics,

Laboratory of Technology and

Strength of Materials,

University of Patras, Greece

Email: kitserpes@upatras.gr
\end{abstract}

\begin{abstract}
A three-dimensional dynamic numerical model was developed, using the commercially available finite element software LS-DYNA to simulate the Low Velocity Impact (LVI) case on bonded joints consisting of woven CFRP adherents. The adhesive failure simulated using the Cohesive Zone Method (CZM), while the failures in the composite material simulated using a progressive damage material model based on Hashin's failure criteria. The numerical results were compared with the corresponding numerical and experimental data found in literature, showing good agreement regarding the damage area and the global structural response. However, the maximum contact force was underestimated by $18.2 \%$ due to premature fiber failure in the lower adherent as a result of tensile bending stresses. In the adhesive layer, the stress distribution was found to alter from tensile near the edge of the lower substrate to compressive close to the edge of the upper substrate. The cohesive failure initiated from the edge under mixed mode loading while it propagated along the overlap length under mode II dominated loading. Following, a study on the effect of the post damage parameters of the CFRP material model to the damage accumulation of the joint was conducted. These parameters were calibrated according to experimental data from literature. The modified model was used for the estimation of residual tensile strength of the bonded joint containing impact induced damage. The results show tensile strength decrease of $16.3 \%$ for the joint with $25.4 \mathrm{~mm}$ overlap length and impact energy of $10 \mathrm{~J}$. Finally, the effect of overlap length and impact energy was studied, in the means of damage accumulation in the CFRP and adhesive material and residual tensile strength of the joint. It was found that increasing the overlap length lead to reduction of the disbonding area due to impact loading resulting in lesser decrease of the residual tensile strength of the joint. For low impact energy of 5 $\mathrm{J}$ the associated damage in the adherents and the adhesive is minimal and doesn't affect the tensile strength of the joint. Increasing the impact energy resulted in significant increase in the damage accumulation of the joint leading to equivalent decrease in the tensile strength.
\end{abstract}

Keywords: Composite Bonded Joints, Low Velocity Impact, Finite Element Analysis, Debonding, Residual Strength

\section{Introduction}

In recent years, the implementation of adhesives in the joining method of composite materials in structural applications in aeronautics has increased due to the many advantages over the traditional mechanical joints. Mechanical joints using bolts/fasteners have to deal with the potential problems such as unevenly distributed load in threads (Zhou et al., 2015a), stress concentration in threads (Zhou et al., 2015b), shear damage of bolts (Zhou et al., 2016), heat shorts for pure metal bolts or brittle fracture for pure ceramic bolts (Zhang et al., 2014), residual stress for novel metal-ceramic composite bolts (Zhou et al., 2015c; 2015d). The use of adhesive bonding comes in conjunction with the establishment of the use of composite materials, as it enables to use them more efficiently. Some features which make adhesive bonding attractive include 
improved appearance, improved aerodynamic surfaces, good sealing, high strength, low weight, low stress concentration, low cost, fatigue and corrosion resistance and cost efficiency (Breuer, 2016; Banea and da Silva, 2009).

The joints are generally designed to carry in-plane loads, although they are prone to transverse impact loading from tool drops, flying debris or fragments. Vaidya et al. (2006) studied experimentally and numerically the mechanical behaviour of single lap bonded joints subjected to transverse Low Velocity Impact (LVI). They noticed that the transverse loading causes greater peel stress concentration in the adhesive layer compared to in-plane loading, due to the considerable bending deflection. They also noted that stress distribution around the crack tip changes from mixed mode to primary mode II as the crack propagates through the adhesive.

Impacts are categorized into low and high velocity. High velocity impact response is dominated by stress wave propagation through the material, in which the structure does not have time to respond, leading to very localized damage. As a result, the most critical failure modes include the formation of shear plug, fiber breakage, penetration and delamination. On the other hand, in LVI, the dynamic structural response of the target is of utmost importance as the contact duration is long enough for the entire structure to respond to the impact. In consequence more energy is absorbed elastically and the damage ranges in a larger area. Typical failure modes in the composite materials during LVI are matrix mode which occurs parallel to the fibers, delamination mode, fiber mode and penetration. Normally, during a LVI, matrix and delamination failures occur in lower impact energies compared to fiber failure and penetration. The impact energy required for each damage mode initiation is affected a lot by the geometry, material properties and boundary conditions.

The events of low velocity impacts are very common in airplanes during maintenance works and it is a matter of concern due to the low visual inspectability of the induced damages and due to their impact on the structural integrity of the joints. In literature, many experimental and numerical studies have been conducted to investigate the mechanical behaviour of composite materials under impact load. However, there have been very limited studies regarding the transverse impact on bonded lap joints in composite structures and often the association between the damages in composite material and adhesive material is not accounted. This study focuses on the damage of composite bonded joints under LVI loading and its associated loss of tensile strength capability. Finite Element (FE) models are implemented for this purpose in LS-DYNA software, to analyze the LVI and the uniaxial tensile loading of the joint. The results obtained by the FE model were compared and validated by experimental LVI data conducted on CFRP joints from de Oliveira et al. (2012), leading to the understanding of the experimental results that can be correlated to numerical simulation (Arrigoni, 2020).

The present paper is divided in four sections. The introduction is followed by the Finite Element modeling section where the developed FE model is presented as well as the adopted theories concerning the composite damage and debonding initiation and propagation. In section 3 the numerical results are presented. In the last section of the paper, the conclusions concerning the work are summarized.

\section{Finite Element Modeling}

\section{FE Model}

The geometry and the loading scenario that are selected for simulation are based on the available experimental data found on literature. In this work, a single-lap joint configuration was modelled with each adherent containing 8 plies of plain weave CFRP material with quasi-isotropic stacking sequence $[(0 / 90) /(45 /-45)] 2 S$. The adhesive material was an epoxy film with $0.21 \mathrm{~mm}$ thickness and $25.4 \mathrm{~mm}$ overlap. Impact experiments were conducted in a drop tower apparatus with cut out dimensions of $150 \times 100$ mm in accordance with ASTM - D7136 standard. The striker has a mass of $1.5746 \mathrm{~kg}$ with hemispherical head with $10 \mathrm{~mm}$ diameter made of high strength aluminium alloy. Impact energy is $10 \mathrm{~J}$ that corresponds to $3.56 \mathrm{~m} / \mathrm{s}$ impact velocity. More details about the problem simulated in the current work can be found in de Oliveira et al. (2012). The testing apparatus can be seen in Fig. 1. The modelled geometry with the basic dimensions are presented in Fig. 2.

The numerical simulation conducted in the LSDYNA FE software, which uses an explicit time integration solution algorithm based on central difference method. The aforementioned solution algorithm favors the solution of short duration dynamic problems like an impact event with high non linearities occurring during material failure.

The composite adherents were modelled using 8noded solid element with 3 DOF per node with reduced integration Element Formulation (ELFORM 1). The film adhesive was modelled using 8-noded cohesive elements (ELFORM 19). The impactor was modelled using 8-noded solid elements with rigid material model (MAT 20) to reduce computational cost without any noticeable differentiation when compared to an elastic material. 


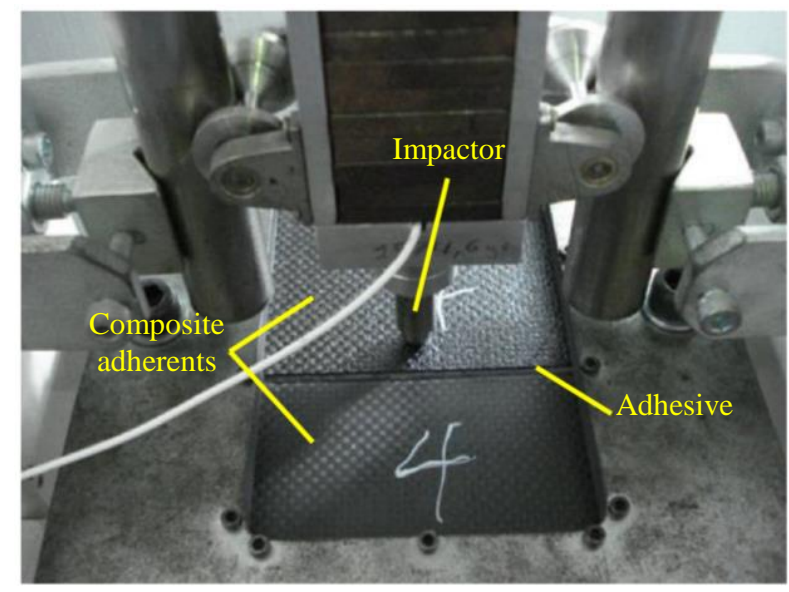

Fig. 1: Drop tower testing apparatus (de Oliveira et al., 2012)

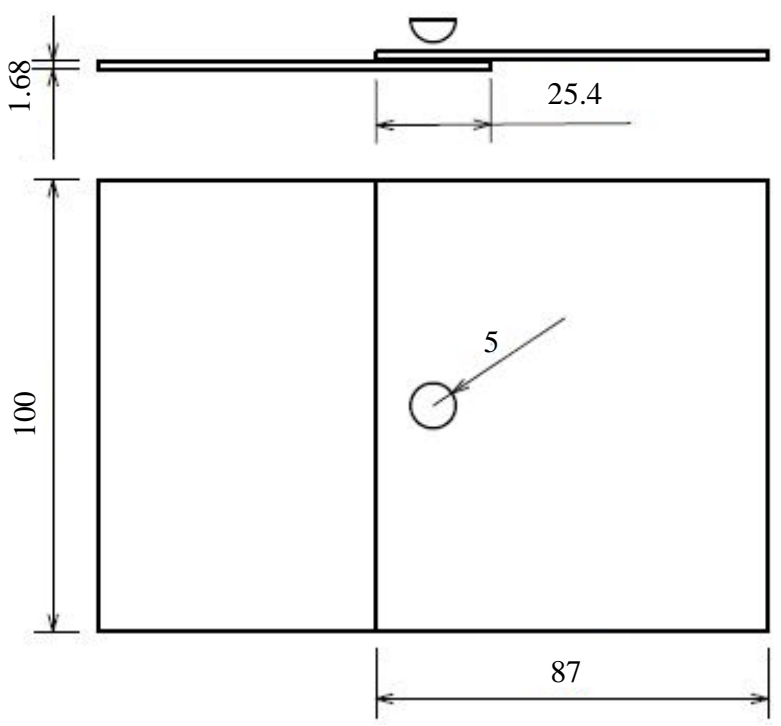

Fig. 2: Drawing of the modeled geometry (in $\mathrm{mm}$ )

In the numerical simulation the available hourglass control algorithms provided by LS-DYNA were tested by their effectiveness preventing the hourglass deformation modes in the underintegrated solid hexahedral elements. Viscous formulations of hourglass control algorithms were generally very ineffective and considered inappropriate for low velocity impacts. The stiffness form of Flanagan and Belytschko (Hallquist, 2006) algorithm (IHQ 4) had better results in preventing the modes. However, it resulted in unrealistic stiffness increase of the structure and high hourglass energy dissipation. The assumed strain co-rotational stiffness form of Belytschko - Bindeman algorithm (IHQ 6) was very effective counteracting the hourglass modes, with low hourglass energy and low stiffness increase. Thus, this algorithm was used in the numerical simulations.

A mass weighted damping was implemented (DAMPING_PART_MASS) on the nodes of the laminate simulating the material damping, to reduce the oscillations during the impact event. Using this type of damping, an external force is applied on each node with magnitude proportional to the nodal velocity and mass and with direction opposite to the nodal velocity. By trial and error, a damping coefficient with value Ds $=800$ is selected.

In the case of transverse impact of the joint, the 4 lower edges of the joint were constrained from lateral (parallel to the edge) and vertical translation, allowing sliding (perpendicular to the edge) and rotation. For the in-plane uniaxial tension case, on one end of the adherent, all translational degrees of freedom of the upper and lower nodes of the adherent were constrained simulating the clamping grips, while the other end was constrained from lateral and vertical translation. Load application was performed in the longitudinal direction on the same nodes via displacement control until the joint failure. Contact was modelled between the impactor and the adherent using the ERODING_SURFACE TO_SURFACE keyword with SOFT $=2$ option which refers to a pinball segment based contact algorithm for the calculation of the contact stiffness.

A non-uniform mesh is used in the numerical calculation, as shown in Fig. 3. The joint contains two mesh refinement regions in the overlap area. The first is away from the point of impact, where the refinement is done only across the overlap length to consider the high stress gradient that occurs in that direction. The second is near the impact area, where the refinement is done in both directions to capture the damage progression of the composite material. On each ply, one element is used in through thickness direction for computational efficiency. The study of the mesh size variation showed significant influence on the dynamic structural response and the failure load of the joint. The strong mesh dependency of the progressive damage modelling method has been reported in other works in literature and referred as significant disadvantage of this method. This is explained by the softening post damage mechanical behavior of the material, which leads to strain localization during material failure resulting in energy dissipation, which depends by the elements' size (Lapczyk and Hurtado, 2007). A mesh convergence study was conducted to find an appropriate element 
size recording the variation of the composite material peak failure load. It was noticed that the required mesh size to achieve convergence depends on the material properties. The baseline model with brittle post damage material properties showed sufficient convergence with 64.351 elements (Fig. 4). On the other side the modified model with more ductile post damage material properties needed further element size decrease with 112.831 elements and thus this mesh size was used for the following simulations.

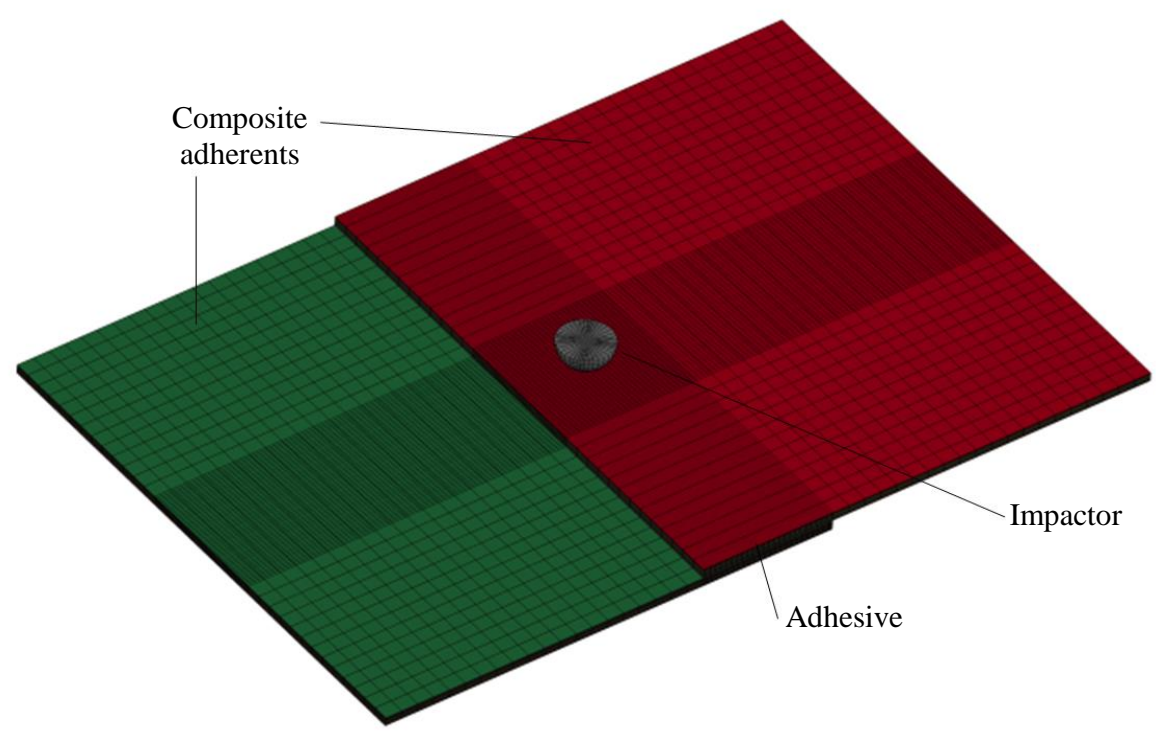

Fig. 3: Mesh of the single lap joint

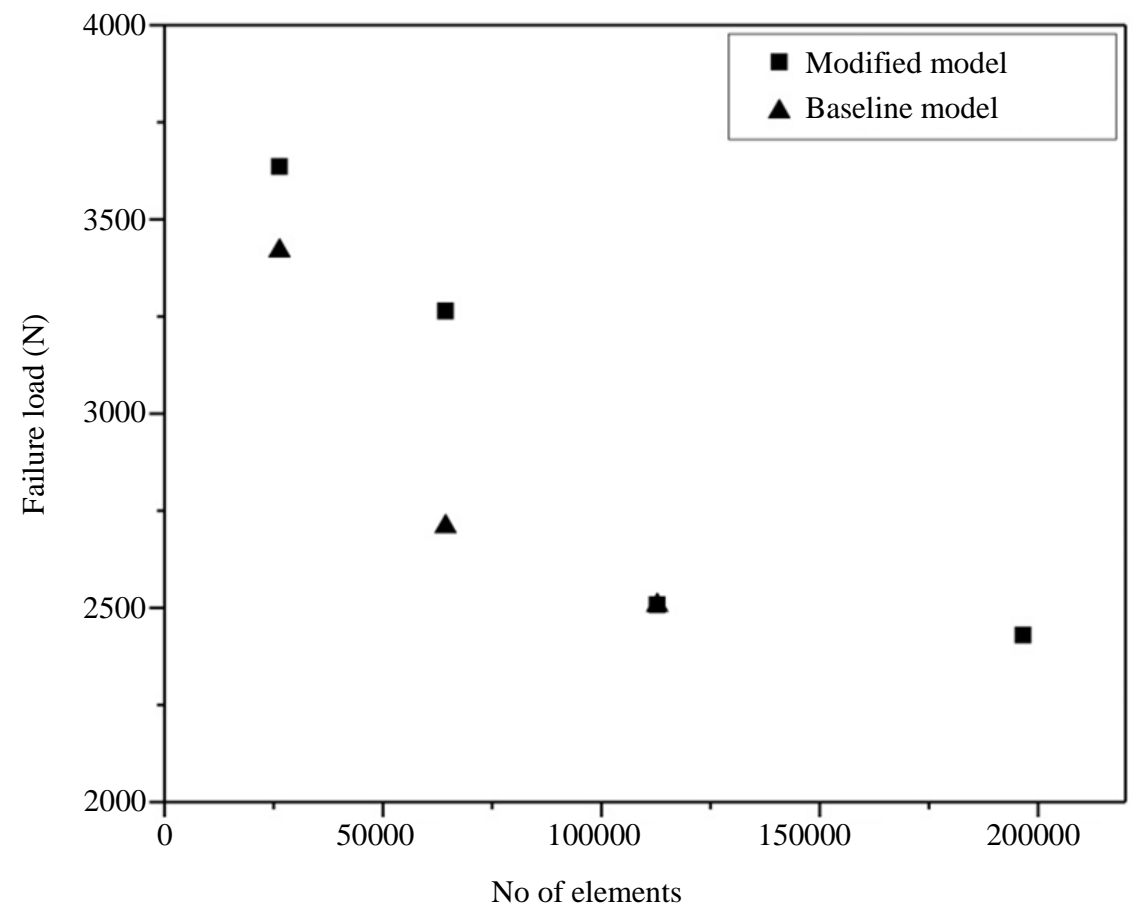

Fig. 4: Failure load-number of finite elements of the mesh convergence study of the model with the baseline and modified material properties 


\section{Progressive Damage Modeling of Composite Material}

Numerical modelling of the composite adherents is done using LS-DYNA material model MAT 162. This material model incorporates strain-based Hashin-type failure criteria (Hashin, 1980) and damage mechanics approach of Matzenmiller et al. (1995) for the characterization of the strain softening behaviour after the damage initiation. It also accounts for strain rates effects in strength and elastic modulus which is useful for simulations of high velocity impacts.

MAT 162 requires a total of 34 material properties and parameters to describe the full response of an orthotropic unidirectional or woven composite material under different damage modes. There are nine elastic constants and ten failure strength properties which can be determined from standard ASTM test methods, except for fiber crush Strength $\left(\mathrm{S}_{\mathrm{FC}}\right)$ and fiber shear Strength $\left(\mathrm{S}_{\mathrm{FS}}\right)$. The rest of material properties are determined by non-standard experimental techniques such low velocity impact experiments and quasi-static punch shear testing in conjunction with supporting numerical simulations. More details regarding the methologies for determination of the material parameters can be found in (Gama, 2015; Xiao et al., 2007; Jordan et al., 2014). A main drawback of this material model is the excessive material testing required to determine all the input parameters. In this work, the post damage parameters of the material model are calibrated by fitting to the experimental structural response and their influence is examined. The values of the required input parameters are presented in Table 1.

More theoretical details and constitutive equations regarding the material model are given below.

A set of quadratic failure functions (Table 2) is used to define the initiation of different damage mechanisms related to fiber fracture, fiber crush, fiber shear, in-plane matrix crack and delamination.

Table 3 and 4, the description of the symbols of Equation (1) to Equation (7) is presented.

Table 1: Values of the input parameters for MAT162

\begin{tabular}{|c|c|c|}
\hline Parameter & Value & Reference \\
\hline$\overline{\mathrm{RO}}$ & $1.58 \mathrm{E}-09$ & - \\
\hline EA & 60800.00 & de Oliveira et al. (2012) \\
\hline EB & 58300.00 & de Oliveira et al. (2012) \\
\hline $\mathrm{EC}$ & 2970.00 & Mendes and Donadon (2014) \\
\hline PRBA & 0.07 & - \\
\hline PRCA & 0.10 & - \\
\hline PRCB & 0.10 & - \\
\hline GAB & 4550.00 & de Oliveira et al. (2012) \\
\hline GBC & 10800.00 & Mendes and Donadon (2014) \\
\hline GCA & 10800.00 & Mendes and Donadon (2014) \\
\hline SAT & 621.00 & de Oliveira et al. (2012) \\
\hline SAC & 760.00 & de Oliveira et al. (2012) \\
\hline SBT & 594.00 & de Oliveira et al. (2012) \\
\hline SBC & 707.00 & de Oliveira et al. (2012) \\
\hline SCT & 75.00 & Mendes and Donadon (2014) \\
\hline SFC & 2000.00 & Deka et al. (2008) \\
\hline SFS & 1000.00 & Deka et al. (2008) \\
\hline SAB & 125.00 & de Oliveira et al. (2012) \\
\hline SBC & 150.00 & Mendes and Donadon (2014) \\
\hline SCA & 150.00 & Mendes and Donadon (2014) \\
\hline SFFC & 0.30 & Deka et al. (2008) \\
\hline AMODEL & 2.00 & Woven option \\
\hline PHIC & 10.00 & Deka et al. (2008) \\
\hline ELIMIT & 1.20 & Deka et al. (2008) \\
\hline S_DELM & 1.00 & Default \\
\hline OMGMX & 0.999 & de Oliveira et al. (2012) \\
\hline ECRSH & 0.001 & Default \\
\hline EEXPN & 4.50 & Default \\
\hline CERATE1 & 0.00 & Default \\
\hline AM1 & 0.90 & de Oliveira et al. (2012) \\
\hline $\mathrm{AM} 2$ & 0.90 & de Oliveira et al. (2012) \\
\hline AM3 & 0.10 & de Oliveira et al. (2012) \\
\hline AM4 & 0.10 & de Oliveira et al. (2012) \\
\hline CERATE2 & 0.00 & Default \\
\hline CERATE3 & 0.03 & Default \\
\hline CERATE4 & 0.03 & Default \\
\hline
\end{tabular}


Table 2: Material model MAT162 failure criteria for woven composite material (Gama, 2015)

\begin{tabular}{ll}
\hline Damage mode & Failure criteria \\
\hline Fiber tension-shear - direction a & $f_{7}-r_{7}^{2}=\left(\frac{E_{a}\left\langle\varepsilon_{a}\right\rangle}{S_{a r}}\right)^{2}+\left(\frac{G_{c a} \varepsilon_{c a}}{S_{a r s}}\right)^{2}-r_{7}^{2}=0$ \\
Fiber tension-shear - direction b & $f_{8}-r_{8}^{2}=\left(\frac{E_{b}\left\langle\varepsilon_{b}\right\rangle}{S_{b T}}\right)^{2}+\left(\frac{G_{b c} \varepsilon_{b c}}{S_{b r s}}\right)^{2}-r_{8}^{2}=0$ \\
Fiber compression - direction a & $f_{9}-r_{9}^{2}=\left(\frac{E_{a}\left\langle\varepsilon_{a}^{\prime}\right\rangle}{S_{a c}}\right)^{2}-r_{9}^{2}=0 \rightarrow \varepsilon_{a}^{\prime}=-\varepsilon_{a}-\left\langle-\varepsilon_{c}\right\rangle \frac{E_{c}}{E_{a}}$ \\
Fiber compression - direction b & $f_{10}-r_{10}^{2}=\left(\frac{E_{b}\left\langle\varepsilon_{b}^{\prime}\right\rangle}{S_{b c}}\right)^{2}-r_{10}^{2}=0 \rightarrow \varepsilon_{b}^{\prime}=-\varepsilon_{b}-\left\langle-\varepsilon_{c}\right\rangle \frac{E_{c}}{E_{b}}$ \\
Crush under compressive pressure & $f_{11}-r_{11}^{2}=\left(\frac{E_{c}\left\langle-\varepsilon_{c}\right\rangle}{S_{F C}}\right)^{2}-r_{11}^{2}=0$ \\
Matrix In-plane shear & $f_{12}-r_{12}^{2}=\left(\frac{G_{a b} \varepsilon_{a b}}{S_{a b}}\right)^{2}-r_{12}^{2}=0$ \\
Parallel matrix mode (Delamination) & $f_{13}-r_{13}^{2}=S^{2}\left\{\left(\frac{E_{c}\left\langle\varepsilon_{c}\right\rangle}{S_{c r}}\right)^{2}+\left(\frac{G_{b c} \varepsilon_{b c}}{S_{b c 0}+S_{S R c}}\right)^{2}+\left(\frac{G_{c a} \varepsilon_{c a}}{S_{c a 0}+S_{S R c}}\right)^{2}\right\}-r_{13}^{2}=0$
\end{tabular}

Table 3: Description of variables of the failure criteria

\begin{tabular}{ll}
\hline Variable & Description \\
\hline$f_{7}, f_{9}$ & Fiber mode failure in a direction \\
$f_{8}, f_{10}$ & Fiber mode failure in b direction \\
$f_{11}$ & Fiber crush failure mode \\
$f_{12}$ & Perpendicular matrix failure mode \\
$f_{13}$ & Delamination mode \\
$r_{7}, r_{9}$ & Damage threshold of fiber mode failure in a direction \\
$f_{8}, f_{10}$ & Damage threshold of fiber mode failure in b direction \\
$f_{11}$ & Damage threshold of fiber crush failure mode \\
$f_{12}$ & Damage threshold of perpendicular matrix failure mode \\
$f_{13}$ & Damage threshold of delamination mode \\
\hline
\end{tabular}

Table 4: Description of parameters of failure criteria

\begin{tabular}{|c|c|}
\hline Parameter & Description \\
\hline$\overline{E_{a}, E_{b}, E_{c}}$ & $\begin{array}{l}\text { Young's modulus in in-plane fill, in-plane } \\
\text { warp and through-thickness direction }\end{array}$ \\
\hline$G_{c a}, G_{b c}$ & Shear modulus in ca and $b c$ plane \\
\hline$\varepsilon_{a}, \varepsilon_{b}, \varepsilon_{c}$ & $\begin{array}{l}\text { Strain in in-plane fill, in-plane warp and through } \\
\text {-thickness direction }\end{array}$ \\
\hline$\varepsilon_{c a}, \varepsilon b c_{c}$ & Strain in ca and $b c$ plane \\
\hline$S_{a T}, S_{b T}$ & $\begin{array}{l}\text { Axial tensile strengths in the fill and } \\
\text { warp directions }\end{array}$ \\
\hline$S_{a C}, S_{b C}$ & $\begin{array}{l}\text { Axial compressive strengths in the fill } \\
\text { and warp directions }\end{array}$ \\
\hline$S_{a F S}, S_{b F S}$ & $\begin{array}{l}\text { Lamina shear strengths due to fiber shear failure } \\
\text { in the fill and warp directions }\end{array}$ \\
\hline$S_{F C}$ & Fiber crush strengths \\
\hline$S_{a T}$ & Through the thickness tensile strength \\
\hline$S$ & Scale factor for delamination criterion, \\
\hline$S_{b c 0}, S_{c a 0}$ & Quasi-static shear strengths \\
\hline$S_{S R C}$ & Shear strength when $\varepsilon_{c}<0$ \\
\hline$S_{a b}$ & Layer shear strength due to matrix shear failure \\
\hline
\end{tabular}

After damage initiation, the progressive damage model assumes linear elastic response which is governed by the reduced stiffness matrix with the updated damage variables $\varpi_{i}$. Damage variable $\varpi_{i}$ with $i=1, \ldots, 6$ is used to relate the onset and growth of damage to stiffness reduction of the material. The compliance matrix $[S]$ is related to the damage variables as:

$$
\left[\begin{array}{cccccc}
\frac{1}{\left(1-\varpi_{1}\right) \mathrm{E}_{a}} & \frac{-v_{b a}}{E_{b}} & \frac{-v_{c a}}{E_{c}} & 0 & 0 & 0 \\
\frac{-v_{a b b}}{E_{a}} & \frac{1}{\left(1-\varpi_{2}\right) \mathrm{E}_{b}} & \frac{-v_{c b}}{E_{c}} & 0 & 0 & 0 \\
\frac{-v_{a c}}{E_{a}} & \frac{-v_{b c}}{E_{b}} & \frac{1}{\left(1-\varpi_{3}\right) \mathrm{E}_{c}} & 0 & 0 & 0 \\
0 & 0 & 0 & \frac{1}{\left(1-\varpi_{4}\right) \mathrm{G}_{a b}} & 0 & 0 \\
0 & 0 & 0 & 0 & \frac{1}{\left(1-\varpi_{5}\right) \mathrm{G}_{b c}} & 0 \\
0 & 0 & 0 & 0 & 0 & \frac{1}{\left(1-\varpi_{6}\right) \mathrm{G}_{c a}}
\end{array}\right]
$$

A damage variable $\omega_{\mathrm{i}}$ for an individual failure mode $j$ is given by:

$$
\varpi_{i}=\max \left\{q_{i j} \phi_{j}\right\}, j=1, \ldots, 5
$$

$\phi_{i}=1-e^{\frac{1}{m}\left(1-\mathrm{r}_{j}^{m}\right)}, r_{j} \geq 1$

The damage variables are coupled to the individual damage modes $(j=1, \ldots, 6)$ by the vector-value function $q_{i j}$ of the form:

$$
[q]=\left[\begin{array}{lllll}
1 & 1 & 1 & 0 & 0 \\
0 & 0 & 1 & 0 & 0 \\
0 & 0 & 1 & 0 & 1 \\
1 & 1 & 1 & 1 & 1 \\
0 & 0 & 1 & 0 & 0 \\
1 & 1 & 1 & 0 & 1
\end{array}\right]
$$




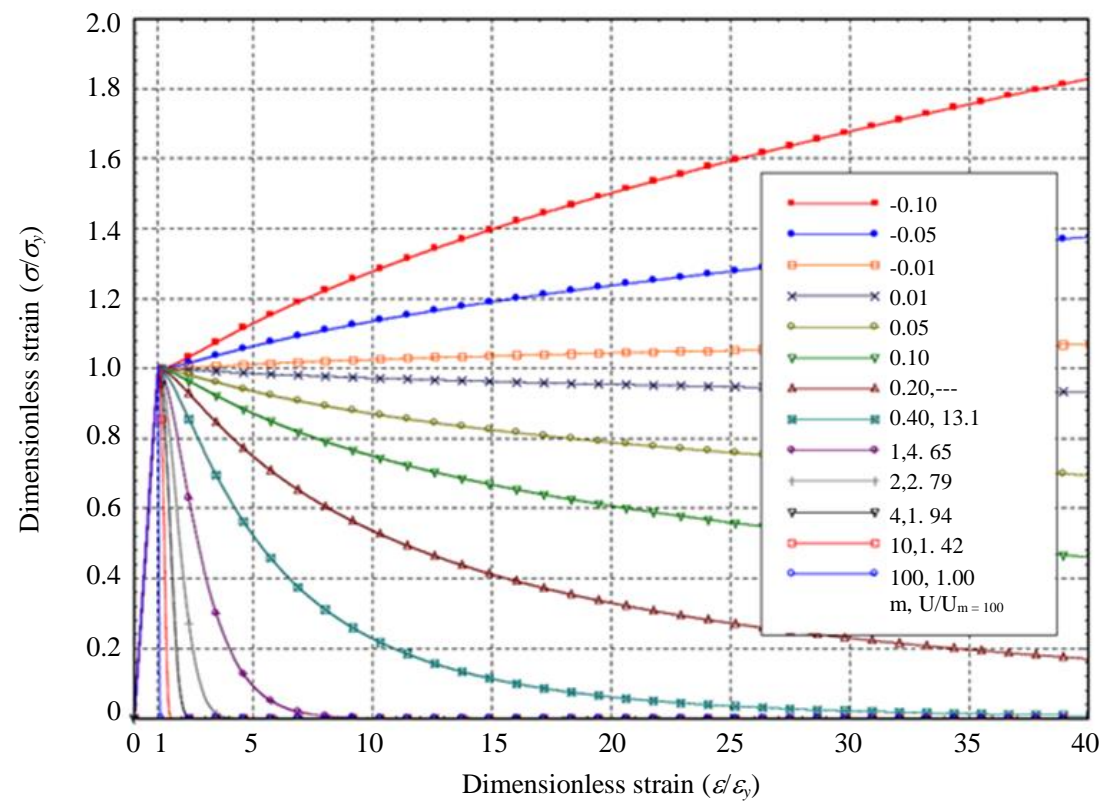

Fig. 5: Dimensionless stress-dimensionless strain curves of MAT162 material model according to the softening parameter $m$ (Gama et al., 2009)

So that:

$$
E_{i}=\left(1-\varpi_{i}\right) E_{i 0}, G_{i}=\left(1-\varpi_{i}\right) G_{i 0}
$$

Where:

$r_{j}=$ Damage threshold,

$\varpi_{i}=$ Damage variable

$m=$ Strain softening parameter

The damage threshold $r_{j}$ is initially set equal to 1.0 to represent the undamaged material and increases as damage accumulates according to equation $r=\frac{\varepsilon}{\varepsilon_{y}}$. The damage variable $\varpi_{i}$ varies from 0 (no damage) to 1.0 (failed), as the $r_{j}$ varies from 1 to infinity according to Equation 10. The moduli are degraded as damage increases according to the Equation 12.

Figure 5 shows the dimensionless stress as a function of dimensionless strain according to Equation 10 for different values of the softening parameter $m$. The exponential law formulation Equation 10 is very versatile as it can model a wide range mechanical behavior like brittle failure, perfect plastic and hardening. For high positive values the postyield stress-strain behavior can be considered as brittle, while for low values it can be considered as ductile. Similarly, values of parameter $m$ around 0 simulate perfect plastic material behavior, while negative values simulate material with hardening post damage behavior.

\section{Cohesive Zone Modeling of Adhesive Material}

Numerical modelling of the epoxy film adhesive is done using LS-DYNA material model MAT 138. This material model simulates the adhesive material with the Cohesive Zone Method (CZM). It includes a bilinear traction-separation law with a quadratic mixed mode delamination criterion. Theoretical details and constitutive laws regarding the CZM, can be found in (LSTC, 2014; Floros et al., 2015).

\section{Results and Discussion}

In the following subsections, the results of the FE models of LVI are presented. For the model in section 3.1, the elastic and strength properties used for the MAT 162 material model of CFRP found on literature from the corresponding author (de Oliveira et al., 2012; Mendes and Donadon, 2014), while for the rest parameters, baseline parameters are used, which was found in Deka et al. (2008). In section 3.2, the critical MAT 162 parameters are calibrated according to the experimental data of the LVI testings. Finally, the influence of the overlap length of the joint and of the impact energy are studied by means of damage accumulation in the joint materials and residual tensile strength of the joint.

\section{Results of the FE Model with Baseline CFRP Material Properties}

Figure 6 the experimental reaction force - time curves for the LVI testings are plotted along with the numerical model of this work. The joint stiffness and the loading part of the response up to failure is in excellent agreement with the experimental results. However, the numerical model underestimates the peak reaction force by $18.2 \%$, due to premature fiber failure in the lower ply, 
due to bending tensile stress. This localized failure instantly propagates through the upper plies inducing further fiber fracture and delamination of the adhesive layer, leading to a sudden decrease of the reaction force. The numerical model also predicts $5.22 \mathrm{~J}$ energy absorption, which is in good agreement (5.7\% deviation) with the mean value of experimental data.
The damaged area in composite and adhesive material predicted by this study has similar shape but it is larger, compared to the numerical results of de Oliveira et al. (2012). This correlates with the premature fiber failure, which results in increase in size of damage to dissipate the remaining impact energy. In Fig. 7 the damage areas of the numerical models are shown in comparison.

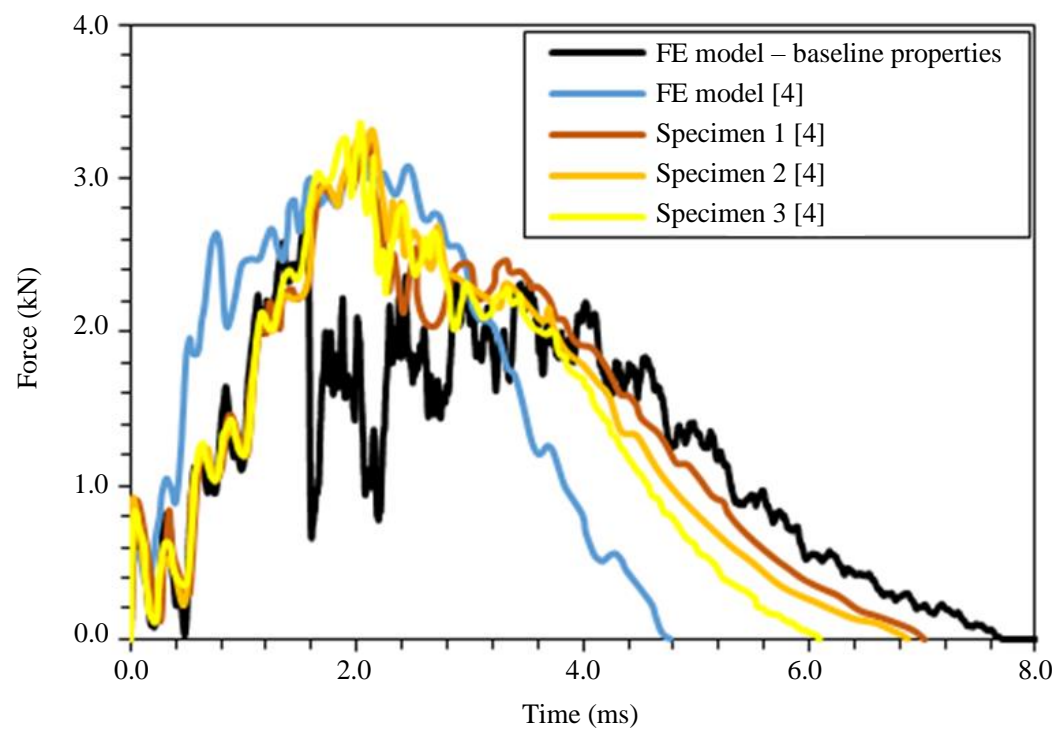

Fig. 6: Comparative contact force - time curves of the LVI from the FE model with baseline material properties and from the numerical and experimental data from de Oliveira el al. (2012)
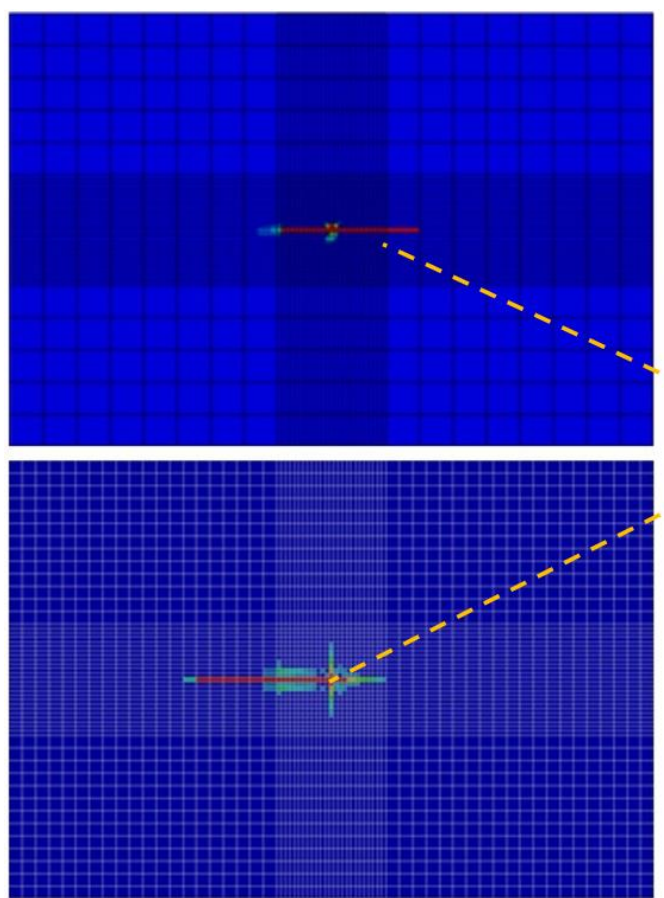

(a)

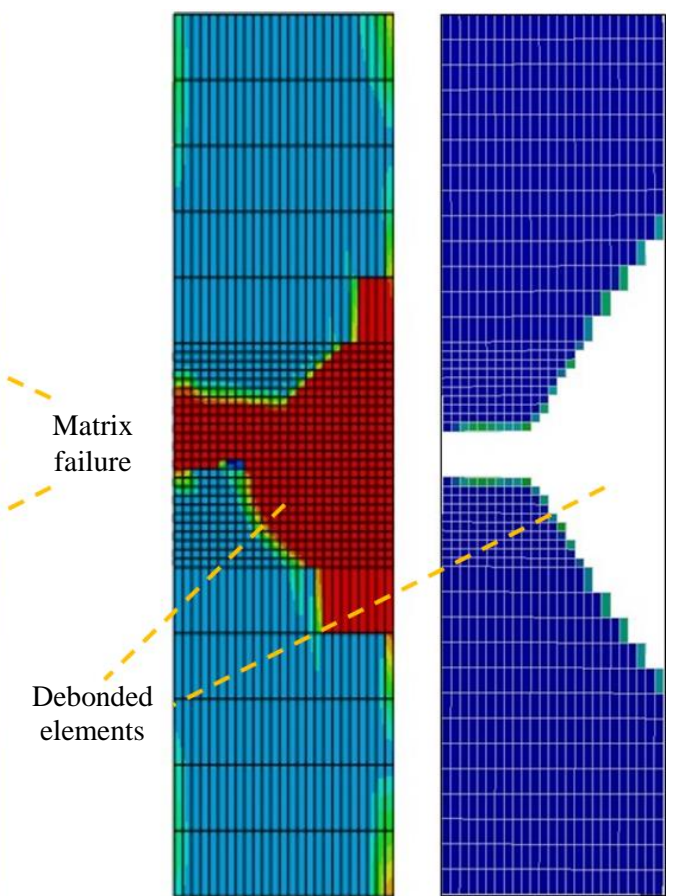

(b)

Fig. 7: Comparison of (a) matrix failure in 1st layer of top laminate and (b) adhesive layer disbonding between the FE model of de Oliveira et al. (2012), (upper and left figures) and the FE model of this work (lower and right figures), (de Oliveira et al., 2012) 
Influence of Properties of CFRP Material on Damage Accumulation of the Lap Joint

For the LVI case, the critical material parameters are determined according to the observed failures and stress field in the FE model and according to the literature references about the typical damages in similar problems. In the next subsections, a study is conducted regarding the influence of these critical material parameters in the structural response and the damage accumulation of the bonded joint.

The critical parameters studied are about the damage softening property of the composite material for fiber failure $\left(m_{1}\right.$ and $\left.m_{2}\right)$ and matrix failure $\left(m_{4}\right)$. Material properties related to strain rate and laminate penetration are estimated to have low influence since the impact velocity is very low and thus not investigated.

\section{Strain Softening Parameter for Damage in Fiber $\left(m_{1}\right.$ and $\left.m_{2}\right)$}

The strain softening parameter for damage in fiber has the biggest influence in this FE model, since this was the main damage, which lead to macroscopic failure of the bonded joint. The tested values are lower related to the baseline model ranging from $m=0.3$ to $m=0.9$. Lowering the values of parameter $\mathrm{m}$, the total strain energy for failure is increasing making the material failure of CFRP more ductile. The woven CFRP material is balanced in the two principal material directions, so $m_{1}=m_{2}=\mathrm{m}$ is assumed.

Figure 8 the force - time curves for the four parameter's values are plotted. The curves are identical in the initial loading region until failure. As expected, lowering the $m$ value, the failure load is increasing. Similarly, delamination area in the adhesive is lowered, especially for the case of $m=0.3$, which further indicated the association between the events of fiber rapture in the low laminate and the adhesive delamination. The absorbed energy for the case of $m=$ 0.3 is $2.43 \mathrm{~J}$, which is much lower from the other cases where it is over $5 \mathrm{~J}$. That happens due to the decrease in damage accumulation of composite material, as shown in Fig. 9 where the area subjected to fiber damage and total fiber failure is represented.

\section{Strain Softening Parameter for Damage in Matrix $\left(m_{4}\right)$}

Figure 10 the force - time curves for the parameter's values which simulate hardening, perfect plastic, ductile softening and brittle softening mechanical behavior of the matrix are plotted. In this graph, it is observed that the models with $m=0.1$ (ductile softening), $m=0.001$ (plastic) and $m=-0.2$ (hardening) have identical response and damage accumulation. On the contrary, on the models with more brittle matrix with $m=0.5$ and $m$ $=1$ there is a big increase in delamination area, since the composite material has reduced resistance in delamination damage growth. In the cases with relatively brittle matrix material, the CFRP also suffered from fiber mode shear damage due to the high transverse shear stresses on the region adjacent to the impact point as shown in Fig. 11. The result of the increased damage accumulation is reflected on the force - time curve with decrease in stiffness on the region with force over $2.5 \mathrm{kN}$ and with decrease in the peak force. However, this is not reflected in the absorbed energy of the joint or in the delamination area of the adhesive.

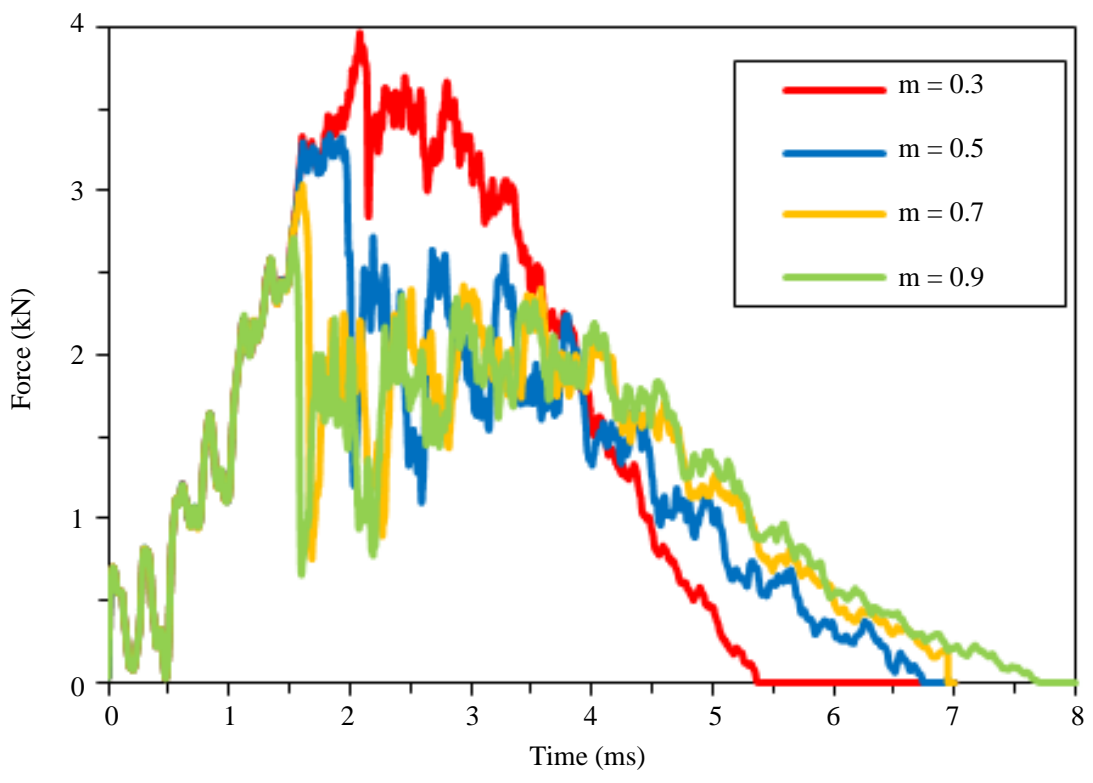

Fig. 8: Contact force - time curves of LVI FE model according to the $\mathrm{m}^{1} / \mathrm{m}^{2}$ fiber damage softening parameter 


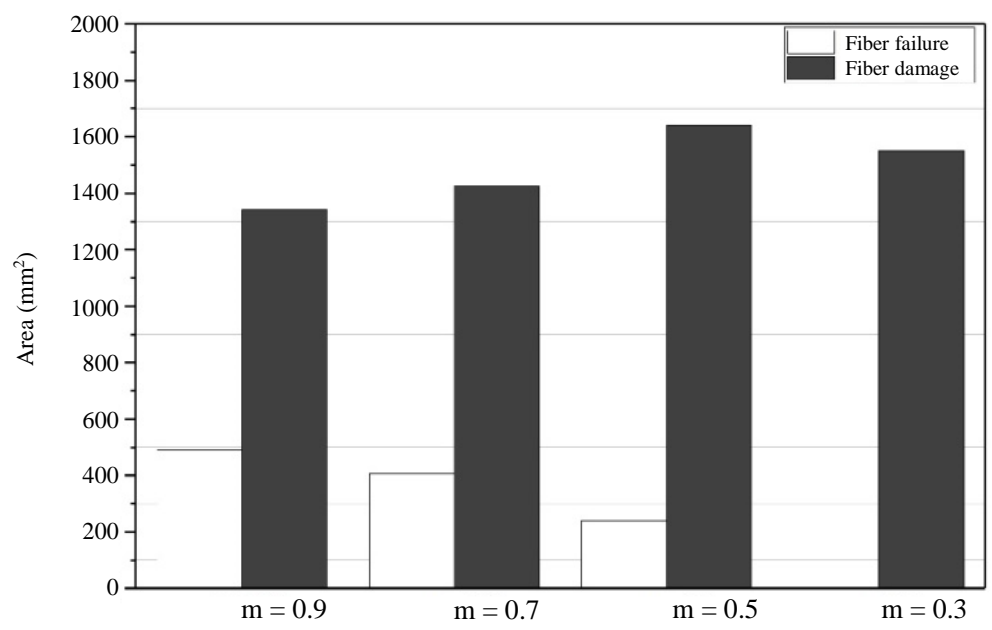

Fig. 9: Fiber damage area on the composite adherents of the LVI FE model according to the $\mathrm{m}^{1} / \mathrm{m}^{2}$ fiber damage softening parameter

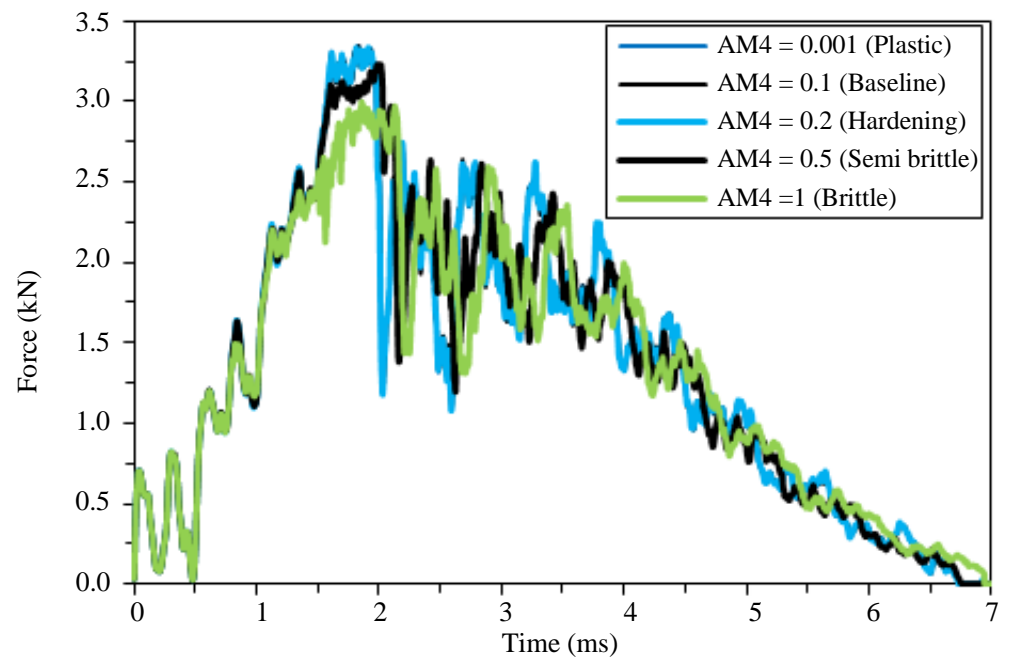

Fig. 10: Contact force - time curves of LVI FE model according to the $\mathrm{m}^{4}$ matrix damage softening parameter

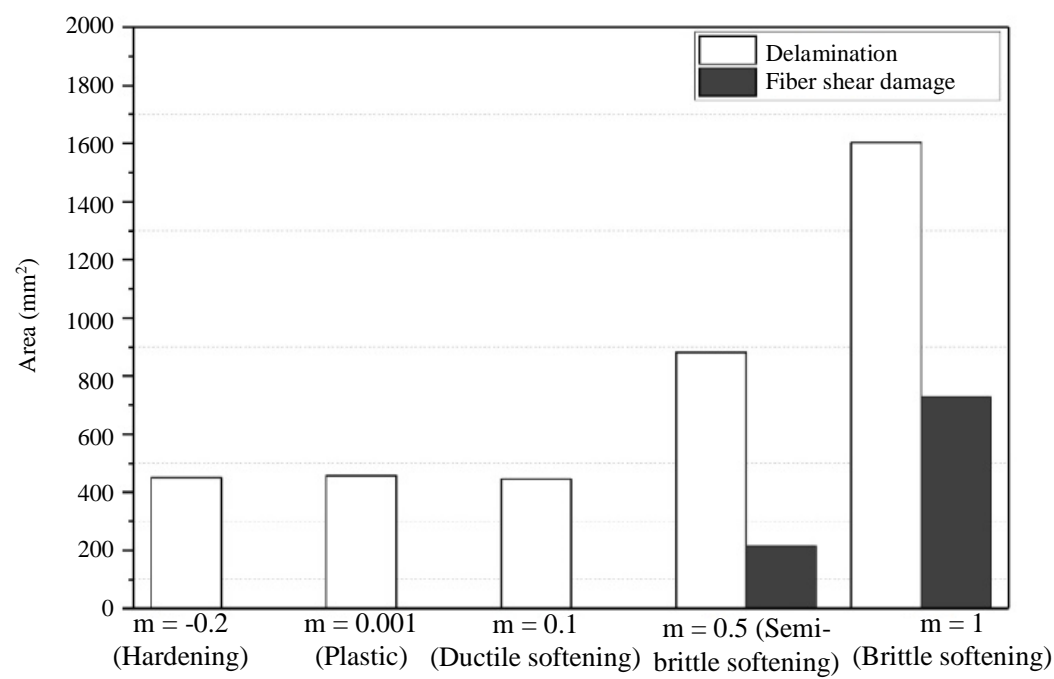

Fig. 11: Delamination and fiber shear damage area on the composite adherents of the LVI FE model according to the $\mathrm{m}^{4}$ fiber damage softening parameter 


\section{Damage Limit Parameter for Elastic Modulus Reduction $\left(\omega_{\max }\right)$}

This material model parameter defines the upper limit of the damage variable $\varpi_{i}$ and thus the minimum value of the reduced elastic modulus according to Equation. 12. The parameter $\omega_{\max }$ affects the mechanical behavior of the material model subjected to high strain.

In the force - time graph (Fig. 12), the influence of $\omega_{\max }$ appears after a main failure occurs in the structure, which results in sudden loss of contact force. At this stage, the damage propagates through the material and the parameter $\omega_{\max }$ acts as a barrier in this occurrence, decreasing the drop in the contact force. The decreased damage growth with smaller values of the parameters is also reflected in the absorbed energy of the joint and the delamination area of the adhesive, which are also lower.

\section{Results of the FE Model with Modified CFRP Material Properties}

The resulted parameters for the CFRP material that are determined from the calibration procedure are $m_{1}=$ $m_{2}=0.3, m_{4}=0.5$ and $\omega_{\max }=0.993$. The modified model had very good correlation with the experimental results as shown in the graph of Fig. 13. The peak force and the stiffness of the modified model is near identical with the experimental data while the post damage response also shows good agreement.

Following the damage progression in the joint during the impact is briefly presented as individual events Fig. 13:

A. Initiation of delamination on the 2 nd ply [ \pm 45$]$ of the top adherent under the impact zone

B. Initiation of adhesive damage under mode II loading on the edge of the overlap
C. Initiation of fiber damage on the last ply [0/90] of the bottom adherent under tensile bending stress and initiation of fiber mode damage due to transverse shear stress on the 2 nd ply [ \pm 45$]$ of the top adherent under the impact zone

D. Initiation of adhesive failure under mixed mode loading on the edge of the overlap

E. Simultaneous propagation of fiber failure and delamination on the lower plies of the top adherent which leads to initiation of adhesive failure under mode II loading and fiber failure on the last ply [0/90] of the bottom adherent

F. Gradual fiber damage propagation on the last ply [0/90], which leads to extensive adhesive failure under mode II loading

G. Abrupt fiber failure propagation under tensile loading of the last ply [0/90] to the upper plies of the bottom adherent and further adhesive failure propagation

When major failure propagation occurs, it is also reflected on the force - time curve with steep decrease of the contact force as in E, F and G. Figure 14 illustrates the progressive adhesive failure on different instants of impact. On moment $\mathrm{D}$, the crack initiates under mixed mode loading with mixity ratio $\beta=1.2$. Due to the significantly lower $G_{c}$ in mode I loading, the out of plane traction governs the adhesive failure. On moment E, adhesive debonding initiates on the region adjacent to impact point under mode II $(\beta=2.4)$ governed loading, as the projectile tends close the adhesive crack due to compressive forces. On moment $F$, the debonding propagates from the overlap edge towards the center of the overlap under mode II $(\beta=3.1)$ loading.

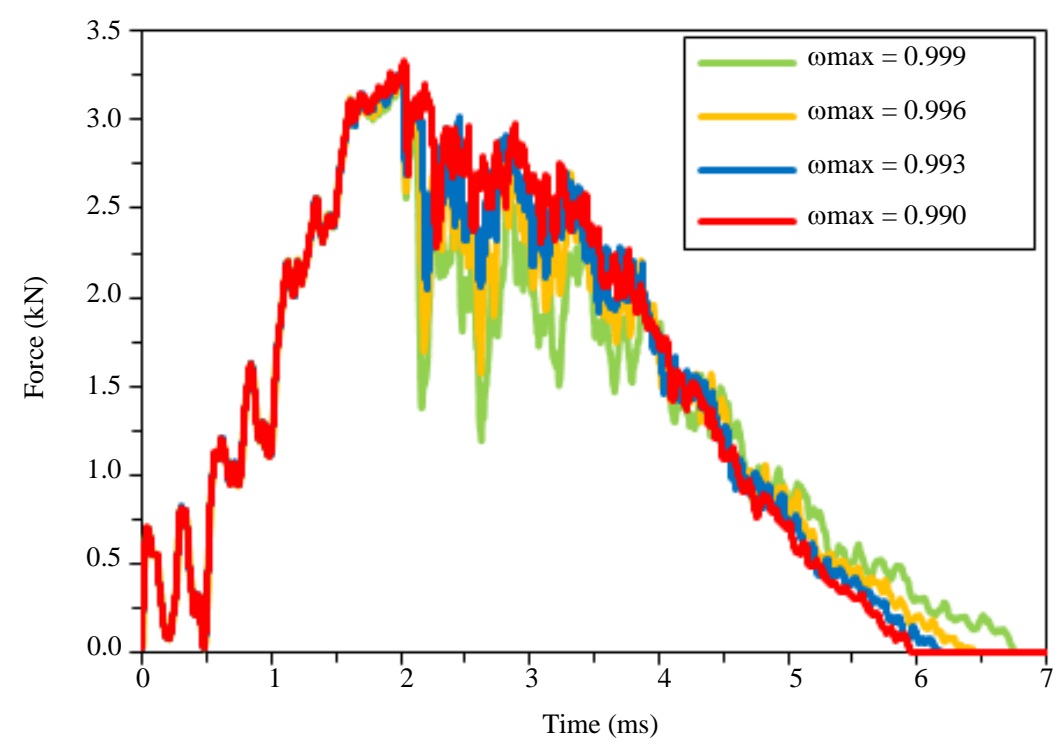

Fig. 12: Contact force - time curves of LVI FE model according to the $\omega$ max damage limit parameter 


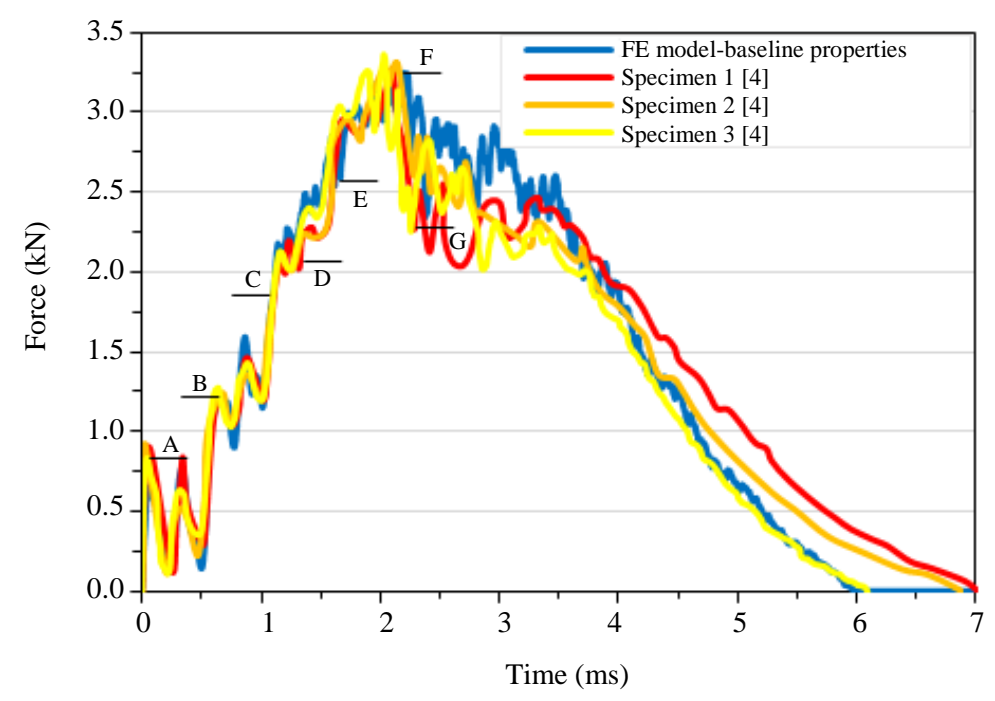

Fig. 13: Comparative contact force - time curves of the LVI from the FE model with modified material properties and from the numerical and experimental data from de Oliveira el al. (2012)

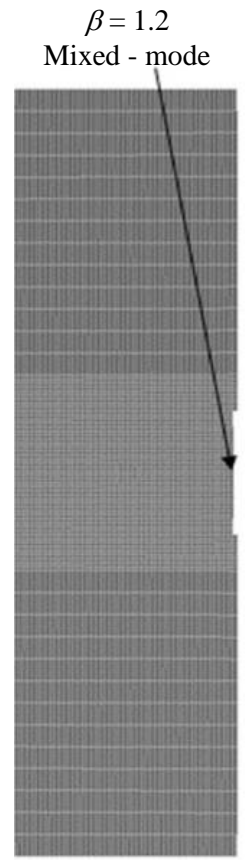

Snapshot D

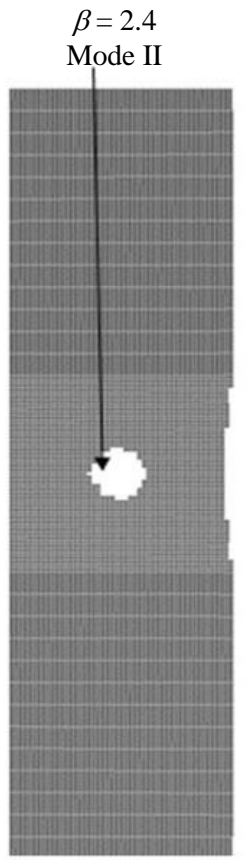

Snapshot E

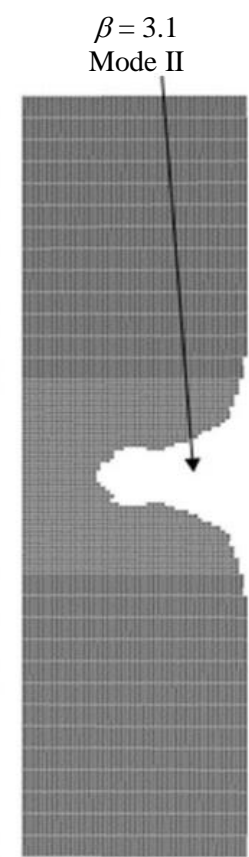

Snapshot F

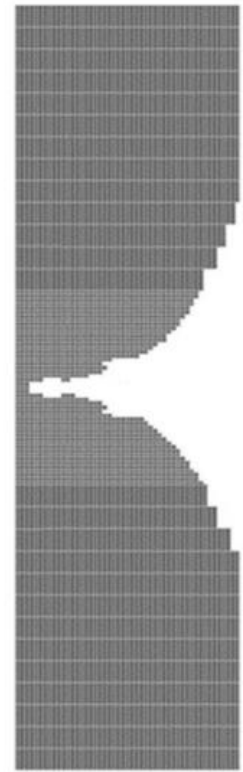

Final snapshot

Fig. 14: Progression of the adhesive debonding during LVI from the FE model with modified material properties

The plies with $0 / 90$ orientation undergo more fiber damage as they are oriented in the bending direction. Concerning the delamination and the fiber mode shear failure, they are developed equally on the internal plies of the top laminate (2nd to 7 th plies). In these plies, the delamination failure forms a circular disk with $9 \mathrm{~mm}$ diameter and the fiber shear failure forms a circular ring with $7 \mathrm{~mm}$ external diameter.

\section{Influence of Overlap Length on Damage Accumulation of the Lap Joint}

As shown in the force - time curves in Fig. 15, increasing the overlap length leads to an increase of the stiffness of the joint. This results in a decrease of the total deflection and in an increase of peak force. Moreover, for the case of overlap length of $25.4 \mathrm{~mm}$, delamination area is $312.7 \mathrm{~mm}^{2}$, while for length of 35 
$\mathrm{mm}$ the delamination area decreases rapidly to the value of $69.3 \mathrm{~mm}^{2}$, which is located adjacent to the impact location and is caused due to local fiber failure. For the case of $15 \mathrm{~mm}$ overlap length a small increase of the delamination area $\left(343 \mathrm{~mm}^{2}\right)$ is noticed.

Figure 16 the force - displacement curves of the uniaxial tensile loading of the damaged and intact joint configurations are plotted. The joint with $35 \mathrm{~mm}$ length has an identical failure load of around $72 \mathrm{kN}$ for the cases with and without damage, which is caused by fiber failure of the composite adherent near the edge of the overlap. The $25.4 \mathrm{~mm}$ joint has a residual tensile strength reduction of $16.3 \%$ with failure mode caused by delamination of the adhesive material. Finally, the 15 $\mathrm{mm}$ joint has reduction of $26.4 \%$ of the tensile strength. It is observed that the damaged joint with $15 \mathrm{~mm}$ overlap length doesn't exhibit sudden failure as the other cases as seen in Fig. 16. On the contrary, the delamination failure occurs in two stages since the propagation of the debonding is blocked temporary until the applied displacement increases, causing total joint failure.

In the uniaxial tension, the adhesive film is loaded by mode II dominated loading with mixity ratio of $\beta \approx 5$ before the formation of a plastic zone on the joint overlap. Before the delamination of the joint, the adhesive film is loaded with mixed mode loading with mixity ratio of $\beta \approx 2$.

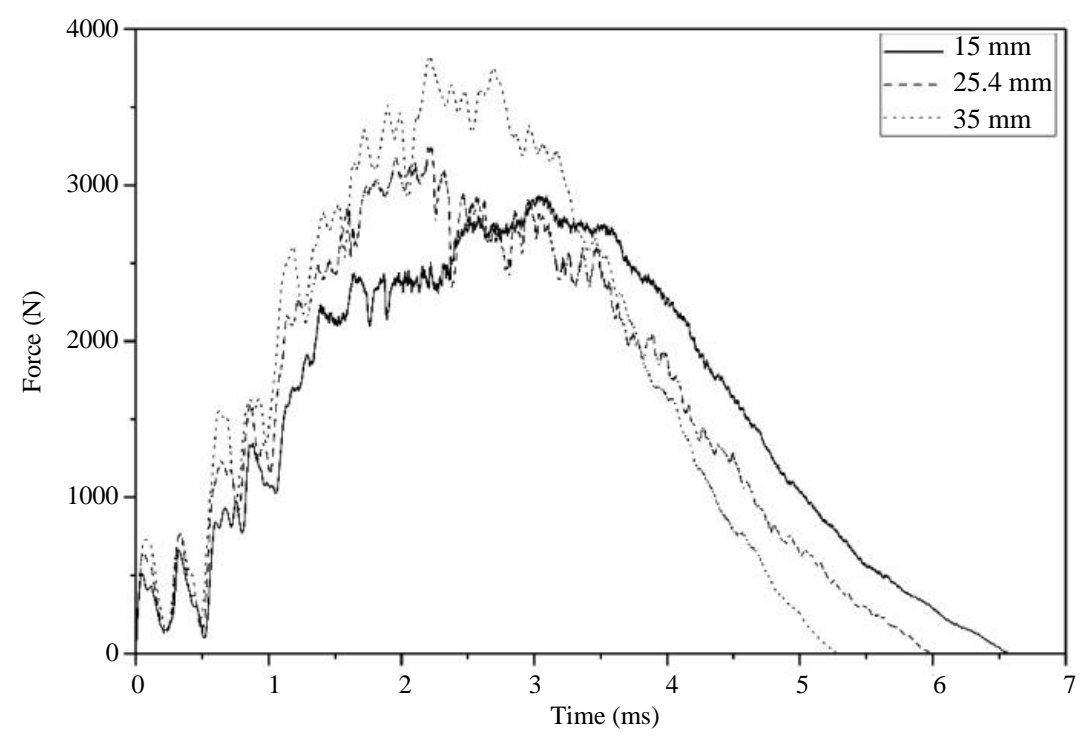

Fig. 15: Contact force - time curves of LVI FE model according to the overlap length

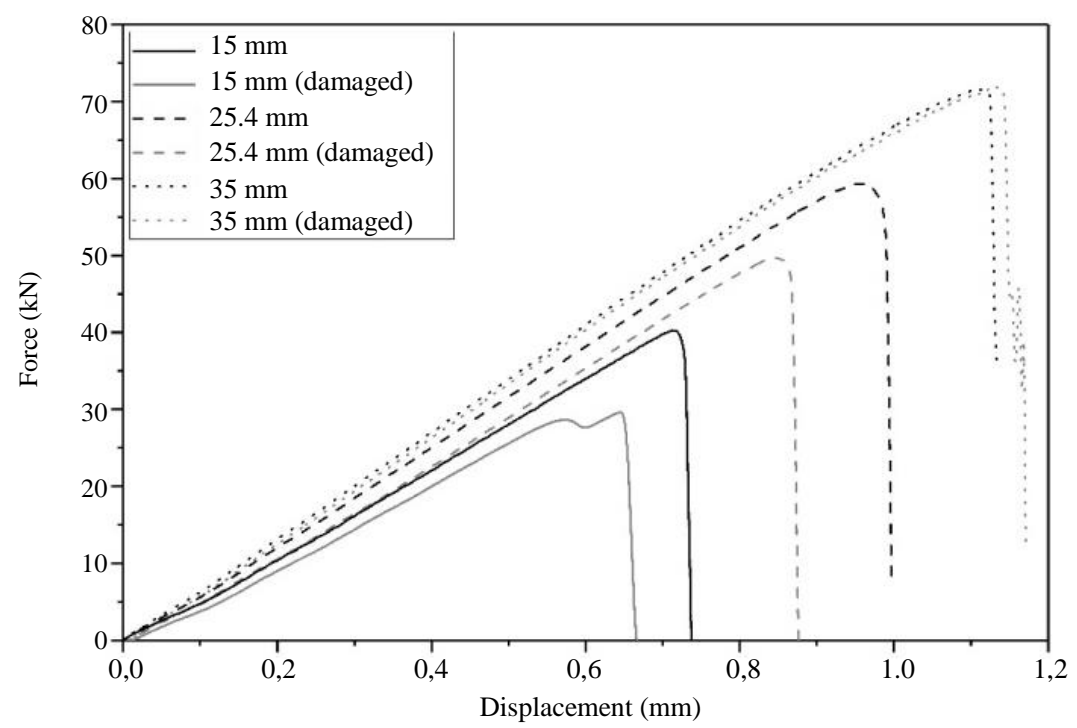

Fig. 16: Force - Displacement of the uniaxial tension FE model according to the overlap length 


\section{Influence of Impact Energy on Damage Accumulation of the Lap Joint}

Increasing the impact energy results in an increase of the peak force during impact, as shown in Fig. 17. The total deflection of the joint is increased but the impact duration is not affected, as it is influenced solely by the joint stiffness and projectile mass. On the $10 \mathrm{~J}$ and $15 \mathrm{~J}$ impact cases, a dramatic increase in damage accumulation of the joint is observed compared to the $5 \mathrm{~J}$ case (Fig. 18). This mechanical behavior indicates the presence of a threshold energy, which after reaching it, the damage propagation in the composite and adhesive material is greatly increased.
Figure 19 the force - displacement curves of the uniaxial tensile loading of the damaged and intact joint configurations are plotted. The failure load for the joint with $5 \mathrm{~J}$ impact energy is identical with the intact joint. This is explained by the minimal damage formation of the joint during the trasnverse impact loading. On the cases with $10 \mathrm{~J}$ and $15 \mathrm{~J}$ impact energy, there is a gradual decrease on the residual tensile strength of the joint by $16.3 \%$ and $23.4 \%$ respectively. From the aformentioned numerical results, in case of high velocity impact, the phenomena would be more localized close to the impact area leading mainly to fiber breakage, penetration and delamination

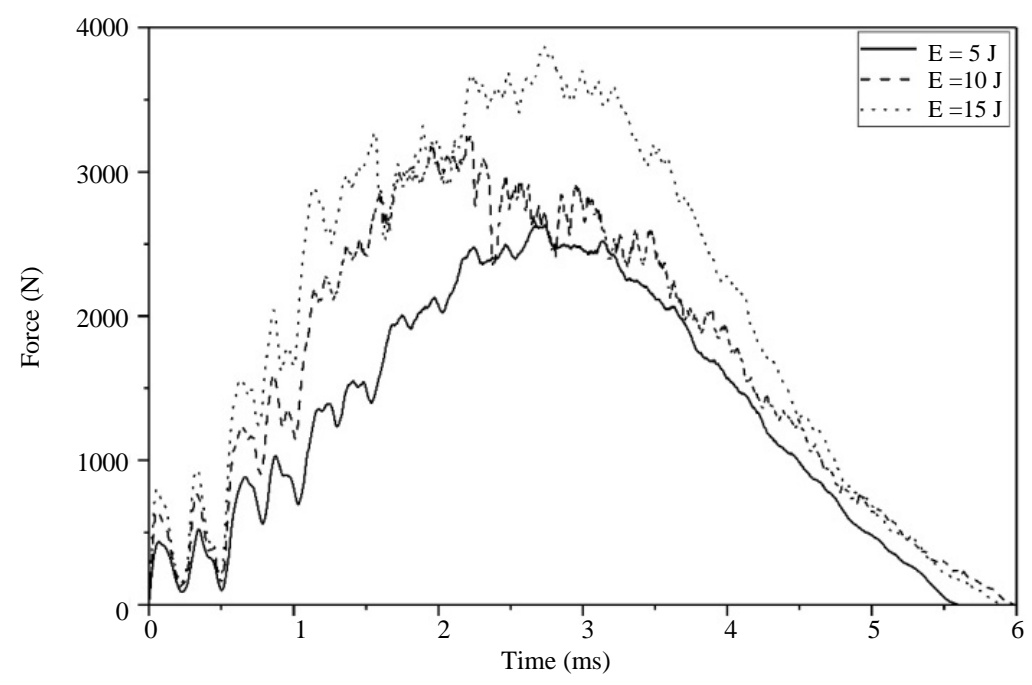

Fig. 17: Contact force - time curves of LVI FE model according to the impact energy

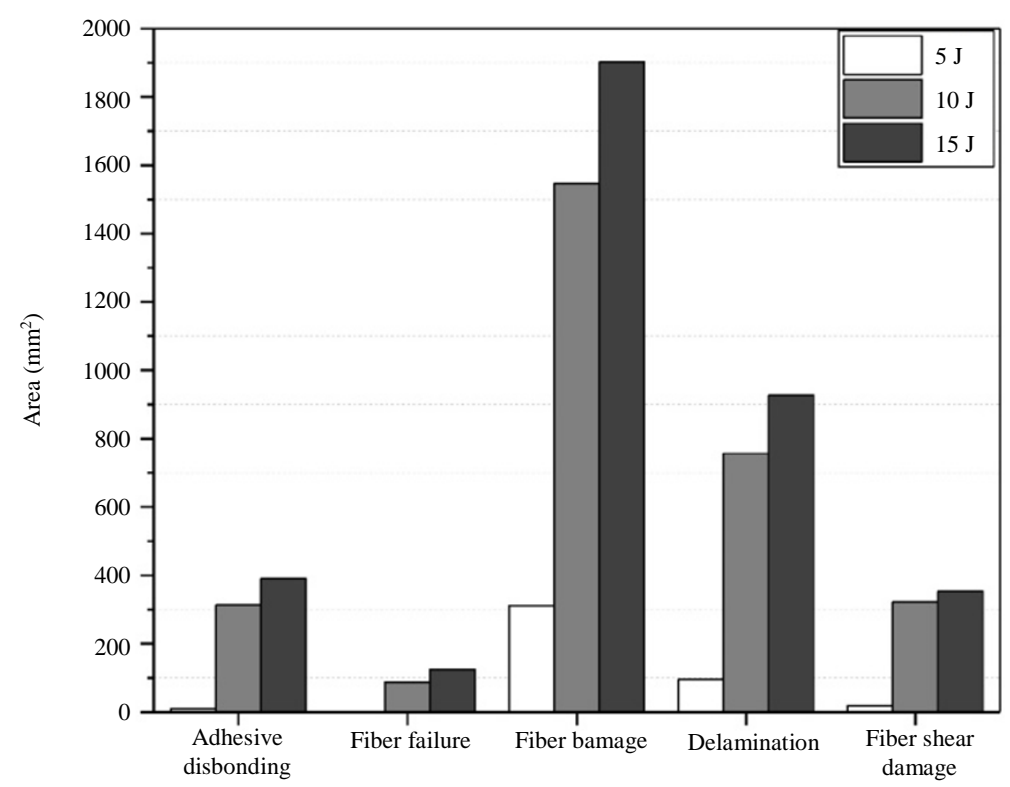

Fig. 18: Damage accumulation on the joint of the LVI FE model according to impact energy 


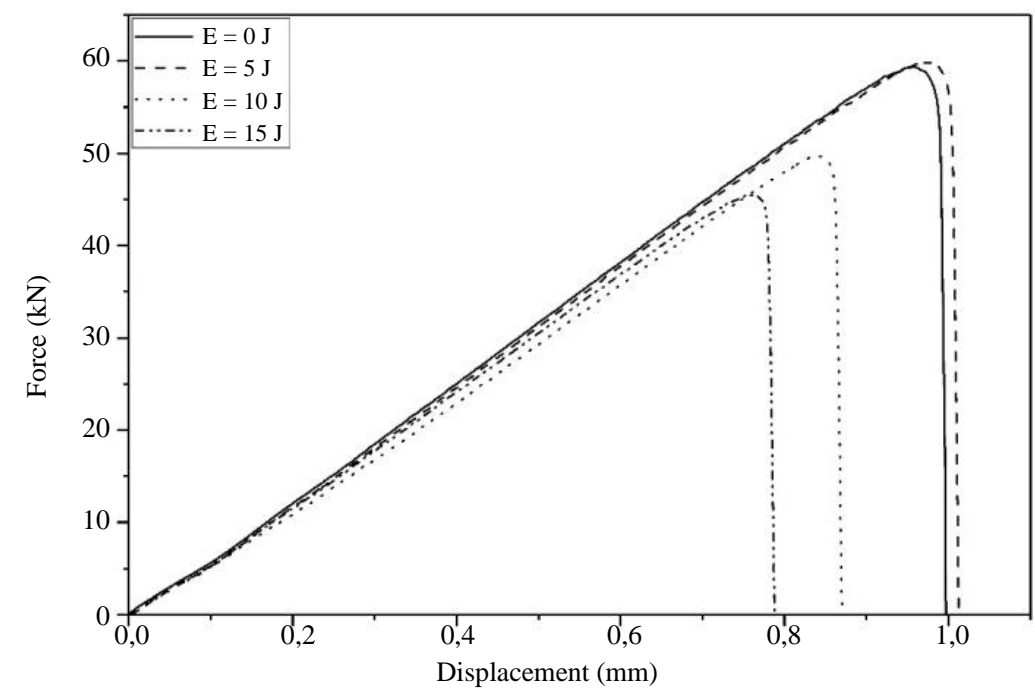

Fig. 19: Force - Displacement of the uniaxial tension FE model according to the impact energy

\section{Conclusion}

Comparing the finite element model of this work with the literature's experimental data, they are in good agreement concerning the stiffness of the joint and the energy absorption (5.7\% deviation) during the impact. The peak force during impact predicted by the model with the baseline material parameters was underestimated by $18.2 \%$ due to fiber failure on the bottom plies of the lower adherent. After the calibration of the CFRP material parameters, very good correlation was achieved regarding the mechanical response of the structure.

The calibration procedure resulted in a composite material with ductile post damage softening mechanical behavior. For a more reliable adjustment of the material parameters, more data are needed like experimental results with different impact energies and data from non destructive testings.

On the mesh sensitivity study, a strong dependence between the mesh size required for convergence and the post damage softening parameters of the composite material was observed. Specifically, for material models with more ductile softening mechanical behavior, the mesh size needs refinement to achieve convergence.

In general, the weak link of the joint studied on this work is the CFRP material due to fiber fracture, which leaded to partial debonding of the adhesive film. The damage of the adhesive film in the transverse impact case initiates from the overlap edge under mixed mode loading and propagates through the overlap length under mode II governed loading. The model predicted that the damage induced by impact loading with $10 \mathrm{~J}$ energy resulted in decrease of the tensile strength of the joint by $16.3 \%$.

On the models with varying overlap length, the joint with increased overlap length had greater stiffness, while the impact induced damage is decreased. On the uniaxial tensile loading model, the joint with $35 \mathrm{~mm}$ overlap length failed due to adherent material tensile fiber failure, while the joints with $25.4 \mathrm{~mm}$ and $15 \mathrm{~mm}$ overlap length failed due to debonding of the adhesive film. The model with $5 \mathrm{~J}$ impact energy had significant decrease of damage accumulation in the joint compared to the models with $10 \mathrm{~J}$ and $15 \mathrm{~J}$, resulting in no reduction of the tensile strength.

\section{Author's Contributions}

Dimitrios Athinaios: Contributed to the FE model development, performance the FE analysis and evaluated the numerical results. Furthermore, the author contributed to the writing of the manuscript.

Konstantinos Tserpes: Designed the research plan, organized the study, evaluated the numerical results and the novelty of the present work. Additionally, the author contributed to the writing of the manuscript.

Giannis Floros: Contributed with Konstantinos Tserpes giving the guidelines the FE model development and analysis and evaluated the numerical results. Additionally, the author edited the manuscript.

\section{Ethics}

This article is original and contains unpublished material. The corresponding author confirms that all of the other authors have read and approved the manuscript and no ethical issues involved.

\section{References}

Arrigoni, M., 2020. Inputs of numerical simulation into the development of shock adhesion tests on advanced materials. 
Banea, M.D. and L.F.M. da Silva, 2009. Adhesively bonded joints in composite materials: An overview. Proc. Inst. Mech. Eng. Part L J. Mater. Des. Applied, 223: 1-18. DOI: 10.1243/14644207JMDA219

Breuer, U.P., 2016. Commercial Aircraft Composite Technology. 1st Edn., Springer, ISBN-10: 3319319183, pp: 257.

de Oliveira, S.A.C., M.V. Donadon and J.R. Tarpani, 2012. Prediction of failures in single lap bonded composite joint subjected to low energy impact loading. Int. J. Veh. Struct. Syst., 4: 123-131.

Deka, L.J., S.D. Bartus and U.K. Vaidya, 2008. Damage evolution and energy absorption of Eglass/polypropylene laminates subjected to ballistic impact. J. Mater. Sci., 43: 4399-4410.

Floros, I.S., K.I. Tserpes and T. Löbel, 2015. Mode-I, mode-II and mixed-mode I+II fracture behavior of composite bonded joints: Experimental characterization and numerical simulation. Compos. Part B Eng., 78: 459-468.

Gama, B.A., 2015. A progressive composite damage model for unidirectional and woven fabric.

Gama, B.A., T.A. Bogetti and J.W. Gillespie Jr, 2009. Progressive damage modeling of plain-weave composites using ls-dyna composite damage model MAT162. Proceedings of the 7th Europe LS-DYNA Conference, (EDC' 09).

Hallquist, J., 2006. LS-DYNA® theory manual.

Hashin, Z., 1980. Failure criteria for unidirectional fibrecomposites. J. Applied Mech., 47: 329-334.

Jordan, J.B., C.J. Naito and B.Z. Haque, 2014. Progressive damage modeling of plain weave $\mathrm{E}$ glass/phenolic composites. Compos. Part B Eng., 61: 315-323.

Lapczyk, I. and J.A. Hurtado, 2007. Progressive damage modeling in fiber-reinforced materials. Compos. Part A Applied Sci. Manuf., 38: 2333-2341.

LSTC, 2014. LS-DYNA keyword user's manual volume II R7.

Matzenmiller, A., J. Lubliner and R.L. Taylor, 1995. A constitutive model for anisotropic damage in fibercomposites. Mech. Mater., 20: 125-152
Mendes, P.A.A.E. and M.V. Donadon, 2014. Numerical prediction of compression after impact behavior of woven composite laminates. Compos. Struct., 113: 476-491.

Vaidya, U.K., A.R.S. Gautam, M. Hosur and P. Dutta, 2006. Experimental-numerical studies of transverse impact response of adhesively bonded lap joints in composite structures. Int. J. Adhes. Adhes., 26: 184-198.

Xiao, J.R., B.A. Gama and J.W. Gillespie, 2007. Progressive damage and delamination in plain weave S-2 glass/SC-15 composites under quasi-static punchshear loading. Compos. Struct., 78: 182-196.

Zhang, R., R. He, W. Zhou, Y. Wang and D. Fang, 2014. Design and fabrication of porous $\mathrm{ZrO}_{2} /\left(\mathrm{ZrO}_{2}+\mathrm{Ni}\right)$ sandwich ceramics with low thermal conductivity and high strength. Mater. Design, 62: 1-6.

Zhou, W., R. Zhang, S. Ai, R. He and Y. Pei et al., 2015a. Load distribution in threads of porous metalceramic functionally graded composite joints subjected to thermomechanical loading. Compos. Struc., 134: 680-688.

Zhou, W., S. Ai, M. Chen, R. Zhang and R. He et al., $2015 \mathrm{~b}$. Preparation and thermodynamic analysis of the porous $\mathrm{ZrO}_{2} /\left(\mathrm{ZrO}_{2}+\mathrm{Ni}\right)$ functionally graded bolted joint. Compos. Part B: Eng., 82: 13-22.

Zhou, W., R. Zhang, S. Ai, Y. Pei and D. Fang, $2015 \mathrm{c}$. Analytical modeling of thermal residual stresses and optimal design of $\mathrm{ZrO}_{2} /\left(\mathrm{ZrO}_{2}+\mathrm{Ni}\right)$ sandwich ceramics. Ceramics Int., 41: 8142-8148.

Zhou, W., H. Zhou, R. Zhang, Y. Pei and D. Fang, 2015d. Measuring residual stress and its influence on properties of porous $\mathrm{ZrO}_{2} /\left(\mathrm{ZrO}_{2}+\mathrm{Ni}\right)$ ceramics. Mater. Sci. Eng. A, 622: 82-90

Zhou, W., R. Zhang and D. Fang, 2016. Design and analysis of the porous $\mathrm{ZrO}_{2} /\left(\mathrm{ZrO}_{2}+\mathrm{Ni}\right)$ ceramic joint with load bearing-heat insulation integration. Ceramics Int., 42: 1416-1424. 